\title{
The Importance of Considering Bird Detectability for Assessing Biological Integrity
}

\author{
Gabriela Menezes Bochio ${ }^{1 *}$ \& Luiz dos Anjos²
}

${ }^{1}$ Programa de Pós-Graduação em Ciências Biológicas, Departamento de Biologia Animal e Vegetal, Universidade Estadual de Londrina - UEL, Londrina, PR, Brasil

${ }^{2}$ Departamento de Biologia Animal e Vegetal, Universidade Estadual de Londrina - UEL, Londrina, PR, Brasil

\begin{abstract}
We propose an index of bird detectability that can improve the selection of more suitable species to be used for evaluating habitat integrity. Bird surveys were conducted in a conservation unit, the Parque Estadual Mata dos Godoy, southern Brazil. We ranked the bird species according to detectability index, which allowed us to establish two groups: species with low detectability (SLD) and species with high detectability (SHD). We also tested some features that are frequently associated with bird species of high detectability. Sound frequency was the attribute more clearly associated with detectability. We found a negative correlation between sound frequency and detectability, especially within certain groups, i.e. Tyrannidae. In our studied system we recognized Aratinga auricapillus as the best biological indicator among the studied birds, due its high vulnerability and high detectability.
\end{abstract}

Key words: Atlantic Forest, Avian Community, Detection Probability, Indicator Species, Sound Frequency.

\section{Introduction}

Detectability is defined as the probability of correctly identifying the presence of one individual of a given species in a particular area (Thompson 2002). The importance of estimating detection probabilities associated with individual or species counts has been highlighted in the literature (Rosenstock et al. 2002). Methods have been developed incorporating detectability, such as distance sampling (Buckland et al. 2008), removal surveys (Farnsworth et al. 2002) and double-observer counts (Nichols et al. 2000).

Factors that may influence detectability are related to behavior and/or the ecology of each bird species. Flock size and body size are behavioral and physical attributes that make them more or less conspicuous to observers (Rosenstock et al. 2002). For example, parrots often fly in large flocks for long distances between feeding and nesting areas are easily detectable (Casagrande \& Beissinger 1997). In contrast, relatively sedentary large birds, such as curassows may be more difficult to record (Jiménez et al. 2003) and, consequently, an inexperienced observer could miss that bird. Anderson (2009), when studying birds in tropical forests suggested that ground species are more detectable than canopy species, which are, therefore

*Send correspondence to: Gabriela Menezes Bochio Programa de Pós-Graduação em Ciências Biológicas, Departamento de Biologia Animal e Vegetal, Universidade Estadual de Londrina - UEL, CP 6001, CEP 86050-990, Londrina, PR, Brasil

e-mail: gabrielabochio@yahoo.com.br significantly underestimated in bird counts. Birds of lower strata and insectivorous birds are cited by Cunningham et al. (1999) as presenting higher levels of detectability.

In surveys in which most detection is by sound, variation may include those attributes related to characteristics of vocalizations such as, singing frequency (regularity of a species sing; Farnsworth et al. 2002) and sound frequency (Alldredge et al. 2007). The observer's ability (Cunningham et al. 1999; Farnsworth et al. 2002) may also influence bird detection. Given the wide range of behaviors and physical attributes among Neotropical birds, it is important to evaluate data about which attributes are more related to high detectability. Moreover, it is important to know how this variable could be incorporated in the process of selecting species for defining indicators for a better evaluation of habitat integrity.

Bird diversity and abundance patterns have been intensively investigated in the fragmented landscape in the Brazilian Atlantic forest of the northern state of Paraná (Anjos et al. 2011). One of those forest fragments is a well-preserved conservation unit, the Parque Estadual Mata dos Godoy (PEMG). The studies in northern Paraná resulted in patterns of sensitivity for several bird species (Anjos 2006) and the occurrence of some of those bird species has been used to assess the biological integrity of forest fragments using an index, called the Index of Biotic Integrity - IBI (Anjos et al. 2009). The composition of the IBI is based on the presence/ absence data of selected bird species (not their abundances) 
in a given area (see Anjos et al. 2009; for more details). The presence/absence of a bird species is closely associated with its detectability, which is one of the most sources of uncertainty in wildlife surveys (Wintle et al. 2004). Thus, it is especially important to avoid the problem of false absence records (Thompson 2002). Thus, the IBI could be improved if the detectability of the key bird species is previously determined, one species should be mainly selected to be used in the IBI if its detectability is high.

Here, we propose a new index for detectability that can help in the selection of species to be used in biological integrity analysis. In addition, we tested biological attributes that tend to increase bird detectability. We hypothesized that detectability is higher in bird species that: 1) live in flocks, 2) inhabit subcanopy (including ground), 3) feed on insects (or arthropods), 4) are smaller in size, 5) are Passerines, and 6) communicate using sounds of lower frequencies. Our analyses support that this index of detectability could improve the selection of more suitable species and consequently, the improvement of the previous IBI (Anjos et al. 2009) by considering the use of detectability.

\section{Material and Methods}

\section{Study site}

The Parque Estadual Mata dos Godoy (PEMG; 23 27’ S and $51^{\circ} 15^{\prime} \mathrm{W}$ ) is a forest fragment of $656 \mathrm{ha}$, located $15 \mathrm{~km}$ south of the Londrina city, state of Paraná, southern Brazil. It is an important conservation unit, preserving a large area of seasonal semideciduous forest with a high biotic integrity (Anjos et al. 2009). Bird counts have been conducted in PEMG for many years, resulting in about 300 bird species recorded (Anjos \& Schuchmann 1997). Samples were carried out on an established U-shaped transect $(3 \mathrm{~km})$. Actually, one trail links two transects of $1 \mathrm{~km}$ each, which are parallel and $300 \mathrm{~m}$ apart. This $\mathrm{U}$-shaped transect is located in the central area of the PEMG, which has a dense canopy and a backlighted midstory and understory.

\section{Bird surveys}

We surveyed birds on transects, monthly, during the breeding season, from September (2009) to April (2010). This period was selected because birds are more active, increasing detectability. We only recorded the species (and not their individual numbers) at any distance of the transect. The observer recorded if the species was seen, heard, or both. Surveys were conducted over 64 days. Each survey began at sunrise, and lasted about four hours. We changed the beginning of the survey each time, so that the end of transect in one day was the beginning in the next day. We did not consider migrants such as the Red-eyed Vireo (Vireo olivaceus) or crepuscular species such as Pauraque (Nyctidromus albicollis).

\section{Procedures for analyses}

We classified all birds recorded in the census into two categories of detectability: 1) species with high detectability (SHD) and 2) species with low detectability (SLD). In order to do this we firstly ranked the species according to the number of days the species was recorded. The median value was used to separate the species into the two groups: the SHD group was composed of species that were detected on more than 15 days, whereas the SLD group was composed of species recorded during less than 15 days. An index of detectability was expressed by dividing the number of days that the species was recorded by the total number of sampled days.

We obtained the information on the birds' attributes from the literature. For the attributes of "social behavior" (species living in pair versus living in flock) and "taxonomic group" (species of passerines versus non-passerines) we used Sick (1997). Stotz et al. (1996) was used to classify the species as either a canopy or subcanopy specie. Insectivores or those that eat other food items follow the classification of Krügel \& Anjos (2000), Anjos (2001), and Anjos et al. (2007). Dunning (2008) was used to classify the species as large-bodied (>80 g) or small-bodied ( $\leq 80 \mathrm{~g})$.

We used the DVD-ROM "Aves do Brasil- Vozes e fotografia" to evaluate the sound frequency of the recorded birds. Sounds were analyzed using the RAVEN Lite 1.0 bioacoustics program. The minimum frequency was the parameter obtained to classify the species into two groups according to sound frequency. We selected $2,000 \mathrm{~Hz}$ as the cut-off. This value was selected because the attenuation of sound waves is more pronounced at frequencies higher than $2,000 \mathrm{~Hz}$ (Schieck 1997). One group of species was thus referred to as "low-frequency birds" $(<2,000 \mathrm{~Hz})$ and the other as "high-frequency birds" $(\geq 2,000 \mathrm{~Hz})$.

\section{Statistical analyses}

We used chi-square contingency table analyses, with appropriate corrections, to evaluate the significance $(\mathrm{p}<0.05)$ of species numbers in categories of detectability versus each attribute (BioEstat 5.0). In order to evaluate the attribute sound frequency, first we ranked the species according to their detectability by plotting the species according to the number of days they were detected. Then, we investigated the relationship between the resulted rank and the sound frequency of the species using the Spearman rank correlation ( $r s)$, calculated in R 2.12.1. We repeated this analysis several times using different bird groups: 1) all species together, 2 ) only the non-Passerines, 3 ) only the Passerines, 4) only the Suboscines Passerines, 5) only the Oscines Passerines, 6) only species of Thamnophilidae, 7) only species of Furnariidae, 8) only species of Tyrannidae, and 9) only species of Tityridae. Due to potential confounding effects of phylogenetic structure in data, the significant tests reported here must be interpreted with caution, and interpretations 
Table 1. Number of species classified in the two categories of detectability (SHD and SLD) and the attributes that were related to these categories for bird species in the Parque Estadual Mata dos Godoy, Southern Brazil.

\begin{tabular}{|c|c|c|c|c|}
\hline \multirow{2}{*}{ Attributes } & \multicolumn{2}{|c|}{ Category of detectability } & \multirow{2}{*}{$\chi^{2}$} & \multirow{2}{*}{ p-value } \\
\hline & SHD & SLD & & \\
\hline \multicolumn{5}{|l|}{ Social behavior } \\
\hline Pair & 48 & 42 & 2.1 & 0.14 \\
\hline Flock & 9 & 17 & & \\
\hline \multicolumn{5}{|l|}{ Stratification } \\
\hline Subcanopy & 44 & 41 & 0.5 & 0.46 \\
\hline Canopy & 13 & 18 & & \\
\hline \multicolumn{5}{|l|}{ Feeding habit } \\
\hline Insectivorous & 30 & 23 & 1.6 & 0.19 \\
\hline Others & 27 & 36 & & \\
\hline \multicolumn{5}{|l|}{ Taxonomic group } \\
\hline Passerines & 36 & 36 & 0.002 & 0.96 \\
\hline Non-Passerines & 21 & 23 & & \\
\hline \multicolumn{5}{|l|}{ Sound frequency } \\
\hline Low $(<2,000 \mathrm{~Hz})$ & 45 & 34 & 5.1 & 0.02 \\
\hline High $(\geq 2,000 \mathrm{~Hz})$ & 12 & 25 & & \\
\hline \multicolumn{5}{|l|}{ Body size } \\
\hline Small $(\leq 80 \mathrm{~g})$ & 38 & 41 & 0.01 & 0.89 \\
\hline Large (>80 g) & 19 & 18 & & \\
\hline
\end{tabular}

should focus more on effect size than in significance tests. We followed nomenclature of the South American Classification Committee of the American Ornithologists' Union.

\section{Results}

We recorded a total of 116 bird species in the present study. The median value of the recorded days was 15 . Therefore, according to our criterion, 57 species were classified as SHD and 59 species as SLD (Appendix ${ }^{*}$ ). Recordings were mainly by sound ( $89 \%)$, followed by birds that were both seen and heard (10\%) and only $1 \%$ of recordings were of birds exclusively seen.

We found no significant differences in the proportion of species numbers in the two groups of species (SHD and SLD) when considering the social behavior, taxonomic group, stratification, feeding habit and body size attributes (Table 1). However, the proportion of birds differed significantly according to the sound frequency attribute. The SHD had a significant higher proportion of birds which emit sounds of low frequency $(\chi=5.125 ; p=0.02$; Table 1$)$.

We found a significant negative correlation between the minimum frequency measured and the total number of days that a species was detected for individual bird groups such as the Passerines ( $r s=-0.24 ; \mathrm{n}=72 ; \mathrm{p}=0.03$.), the Suboscines Passerines ( $r s=-0.39 ; \mathrm{n}=49 ; \mathrm{p}=0.005)$ and the Tyrannidae family ( $r s=-0.79 ; \mathrm{n}=12 ; \mathrm{p}=0.002$; Table 2 ).

*See Appendix in the additional supporting information, available at www.abeco.org.br
Table 2. Spearman rank correlation $\left(r_{s}\right)$ between sound frequency (value of minimum frequency measured) and the number of days that a bird was detected, for various groups sampled in the Parque Estadual Mata dos Godoy, Southern Brazil. $N$ indicates the species number considered in each case.

\begin{tabular}{lccc}
\hline \multicolumn{1}{c}{ Groups } & $r s$ & $N$ & p-value \\
\hline All birds & -0.19 & 116 & 0.03 \\
Non-passerines & -0.19 & 44 & 0.2 \\
Passerines & -0.24 & 72 & 0.03 \\
Oscines passerines & 0.045 & 23 & 0.83 \\
Suboscines passerines & -0.39 & 49 & 0.005 \\
Thamnophilidae & 0.26 & 6 & 0.61 \\
Furnariidae & -0.37 & 16 & 0.14 \\
Tyrannidae & -0.68 & 17 & 0.002 \\
Tityridae & 0 & 5 & 1 \\
\hline
\end{tabular}

Only seven species were detected in all of 64 days of sampling: Baryphthengus ruficapillus, Melanerpes flavifrons, Pionus maximiliani, Hypoedaleus guttatus, Sittasomus griseicapillus, Cyclarhis gujanensis and Basileuterus culicivorus. However, 19 species were recorded only once: Aramides saracura, Patagioenas maculosa, Claravis pretiosa, Nonnula rubecula, Picummus cirratus, Campylorhamphus trochilirostris, Caracara plancus, Coccyzus melacoryphus, Cichlocolaptes leucophrus, Xenops rutilans, Synallaxis frontalis, Hemitriccus obsoletus, Phyllomyias burmeisteri, Cnemotriccus fuscatus, Legatus leucophaius, Pachyramphus polychopterus, Cyanocorax chrysops, Troglodytes aedon and Dacnis cayana. 


\section{Discussion}

Our results potentially improve the efficiency of the IBI proposed by Anjos et al. (2009). Based on the index of detectability proposed here, it was possible to recognize which species would be more suitable for the composition of IBI. In the study by Anjos et al. (2009), thirty bird species were selected to compose the IBI: ten with low sensitivity to forest fragmentation, ten with medium sensitivity, and ten with high sensitivity. However, three species in both levels low sensitivity and medium sensitivity presented lower values of detectability and should be replaced by others with higher ones. Then, the species with low sensitivity Crypturellus parvirostris, Thamnophillus caerulencens and Conopophaga lineata indicated by Anjos et al. (2009) to compose IBI should be replaced by Pionus maximiliani, Dysithamnus mentalis and Leptopogon amaurocephalus. At the same time, the species with medium sensitivity Ramphastos dicolorus, Chamaezia campanisona and Xiphocolaptes albicollis, should be replaced by Pyrrhura frontalis, Cacicus haemorrhous and Sirystes sibilator.

All species with high sensitivity to forest fragmentation, based in Anjos et al. (2009) presented low detectability or were not recorded in the present study; for these species it is not possible to suggest a replacement in the index. There is only one exception, Aratinga auricapillus, which presented high sensitivity and high detectability. Actually, Aratinga auricapillus could be considered the best biological indicator among birds of forest fragments with higher biological integrity in the study region. Overall, we believe that the replacement of the six species mentioned above would improve the IBI, even taking into account the poorly detectable high sensitivity species.

Our results suggest that an important attribute that could increase bird detectability is associated with sound frequency. Birds with higher sound frequency present lower detectability because higher frequency sounds attenuate more rapidly in forest habitats (Alldredge et al. 2007). We found that a greater number of species classified as SHD were birds using sounds with low frequency. In contrast, Cranioleuca obsoleta and Xenops rutilans, which presented the highest sound frequencies, had low detectability. Such tendency may explain the correlation between the measured values of sound frequency and the total number of days that a bird was detected. However, this tendency was not uniform among all bird groups. The strongest tendency was found in the family Tyrannidae. The reason for this is unclear at the moment, but could be related to the social behavior of this bird group.

Although we evaluated the attributes separately, it is clear that some of them are not independent and further investigation on these more complex patterns may be required. For example, a negative relationship between body size and sound frequency in birds has been described in the literature (Wallschläger 1980). Larger birds tend to produce low sound frequencies. However, the largest birds in this study (Penelope superciliaris and Micrastur semitorquatus), which had sounds with low frequency, presented low detectability.

Some species are known to follow mixed flocks, such as Platyrhinchus mystaceus and Tolmomyias sulphurescens (Ghizoni-Junior \& Azevedo 2006). It could increase detectability, because closer species produce more movements and, potentially, may draw the attention of an observer. We did not evaluate the role of mixed flocks in the detectability, but the interference of this behavior should be higher in areas closer to the Equator (Jullien \& Thiollay 1998). Another important factor that could increase detectability is the local abundance; a species with higher local abundance could be easier to detect than other with lower abundance. Of course that an important point that should be also considered is the experience of the observer; an observer with limited knowledge of the local avifauna could introduce significant bias in the indexes by missing the bird contacts.

The patterns of species' detectability described here have limited application in other regions of the Brazilian Atlantic forest due to differences in the forest composition, occurrence of birds with different local reproductive dynamics and/or variations in local abundances. Nevertheless, we highlighted in this study the importance of determining the index of detectability of birds before the application of biological indexes, such as IBI. Such procedures are important to the rapidly access to the biological integrity of different areas, a key point to establish conservation priorities in a fragmented forest landscape.

\section{Acknowledgments}

Financial support for this study was received from CNPq (Brazilian Council for Development of Science and Technology, Brasilia) through the Biological Science Postgraduate Program (first author) and a research grant (second author, 305593/07-2). Research grant (first author) from Fundação Araucária (Curitiba) was received during the study. We thank The Environmental Institute of Paraná State (Curitiba) for permission to work in the Parque Estadual Mata dos Godoy. We also thank the two anonymous reviewers for their helpful comments on earlier version of the manuscript.

\section{References}

Alldredge MW, Simons TR \& Pollock DKH, 2007. Factors affecting detections of songbirds. Ecological Applications, 17:948-955. http://dx.doi.org/10.1890/06-0685

Anderson DL, 2009. Ground versus canopy methods for the study of birds in tropical forest canopies: implications for ecology and conservation. Condor, 111:226-237. http://dx.doi.org./10.1525/cond.2009.090032

Anjos L, 2001. Bird communities in five Atlantic forest fragments in southern Brazil. Ornitologia Neotropical, 12:11-27. 
Anjos L, 2006. Bird species sensitivity in a fragmented landscape of Atlantic forest in southern Brazil. Biotropica, 38:229-234. http://dx.doi.org/10.1111/j.1744-7429.2006.00122.x

Anjos L \& Schuchmann K, 1997. Biogeographical affinities of the avifauna of the Tibagi river basin, Paraná drainage system, southern Brazil. Ecotropica, 3:43-65.

Anjos L et al., 2007. The importance of riparian forest for the maintenance of bird species richness in an Atlantic forest remnant, southern Brazil. Revista Brasileira de Zoologia, 24:1078-1086. http://dx.doi.org/10.1590/ S0101-81752007000400027

Anjos L et al., 2009. Sobre o uso de níveis de sensibilidade de aves à fragmentação florestal na avaliação da integridade biótica: um estudo de caso no norte do Estado do Paraná, sul do Brasil. Revista Brasileira de Ornitologia, 17: 28-36.

Anjos L et al., 2011. Bird species abundance-occupancy patterns and sensitivity to forest fragmentation: Implications for conservation in the Brazilian Atlantic Forest. Biological Conservation, 144:2213-2222. http://dx.doi/10.1016/j. biocon.2011.05.013

Buckland ST, Marsden SJ \& Green RE, 2008. Estimating bird abundance: making methods work. Bird Conservation International, 18:91-108. http://dx.doi/10.1017/ S0959270908000294

Casagrande DG \& Beissinger SR, 1997. Evaluation of four methods for estimating parrot population size. Condor, 99:445-457.

Cunningham RB et al., 1999. Quantifying observer heterogeneity in bird counts. Australian Journal of Ecology, 24:270-277. http://dx.doi/10.1046/j.1442-9993.1999.00971.x

Dunning JBJ, 2008. Handbook of avian body masses. United States of America: Taylor \& Francis Group, LLC.

Farnsworth GL et al., 2002. A removal model for estimating detection probabilities from pointcounts surveys. Auk, 119:414-425. http://dx.doi. org/10.1642/0004-8038(2002)119[0414:ARMFED]2.0CO;2

Ghizoni-Junior IR \& Azevedo MAG, 2006. Composição de bandos mistos de aves florestais de sub-bosque em áreas de encosta e planície da Floresta Atlântica de Santa Catarina, sul do Brasil. Biotemas, 19:47-53.

Jiménez I, Londoño GA \& Cadena CD, 2003. Efficiency, bias, and consistency of visual and aural surveys of curassows (Cracidae) in tropical forests. Journal of Field Ornithology, 74:210-216. http://dx.doi.org/10.1648/0273-8570(2003)074[0210:EBAC OV]2.0.CO;2

Jullien M \& Thiollay J, 1998. Multi-species territoriality and dynamic of neotropical forest understorey bird flocks. Journal of Animal Ecology, 67:227-252. http://dx.doi. org/10.1046/j.1365-2656.1998.00171.x

Krügel MM \& Anjos L, 2000. Bird communities in forest remnants in the city of Maringá, Paraná State, southern Brazil. Ornitologia Neotropical, 11:315-330.

Nichols JD et al., 2000. A double-observer approach for estimating detection probability and abundance from point counts. Auk,117:393-408. http://dx.doi. org/10.1642/0004-8038(2000)117[0393:ADOAFE]2.0.CO;2

Rosenstock SS et al., 2002. Landbird counting techniques: current practices and an alternative. Auk, 119:46-53. http://dx.doi. org/10.1642/0004-8038(2002)119[0046:LCTCPA]2.0.CO;2

Sick H, 1997. Ornitologia Brasileira. Rio de Janeiro: Editora Nova Fronteira.

Schieck J, 1997. Biased detection of bird vocalizations affects comparisons of bird abundance among forested habitats. Condor, 99:179-190.

Stotz DF, Fitzpatrick JM \& Parker III TA, 1996. Neotropical Birds: ecology and conservation. Chicago: University of Chicago Press.

Thompson WL, 2002. Towards reliable bird surveys: accounting for individuals presented but not detected. Auk, 119:18-25. http://dx.doi.org/10.1642/0004-8038(2002)119[0018:TRBS $\mathrm{AF}] 2.0 . \mathrm{CO} ; 2$

Wallschläger D, 1980. Correlation of song frequency and body weight in passerine birds. Cellular and Molecular Life Sciences, 36:412. http://dx.doi.org/10.1007/BF01975119

Wintle BA et al., 2004. Precision and Bias of methods for estimating point survey detection probabilities. Ecological Applications, 14:703-712. http://dx.doi.org/10.1890/02-5166

Received: November 2011

First Decision: February 2012 Accepted: April 2012 